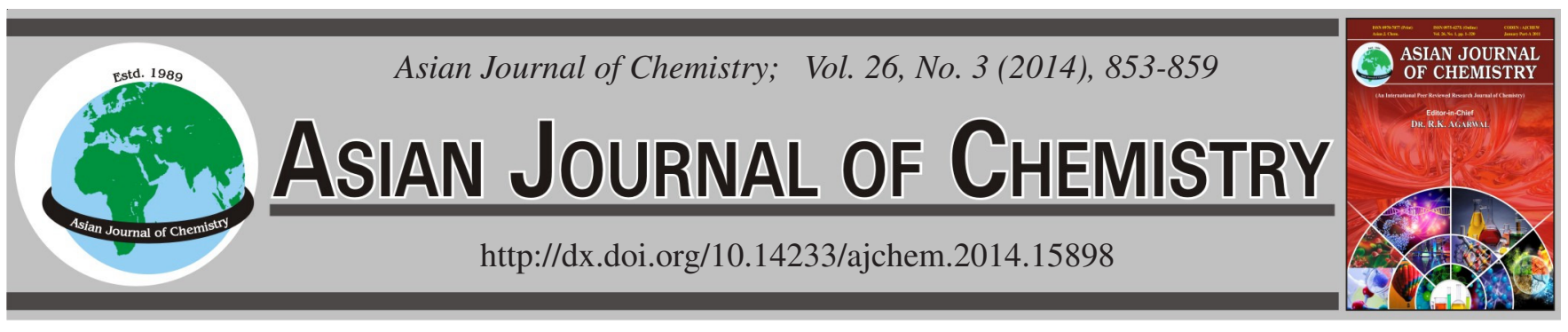

\title{
Oxidative Degradation of Phenol by Corona Dielectric Barrier Discharge at Gas-Liquid Interphase
}

\author{
LeI WANG ${ }^{1, *}$ XIN $\mathrm{YU}^{2}$, GUOXIN $\mathrm{Li}^{1}$ and DAILIN $\mathrm{Li}^{1}$
}

${ }^{1}$ College of Environmental Science \& Engineering, Xiamen University of Technology, Xiamen, P.R. China

${ }^{2}$ Key Laboratory of Urban Environment and Health, Institute of Urban Environment, Chinese Academy of Sciences, Xiamen, P.R. China

*Corresponding author: Fax: +86 592 6291138; Tel: +86 592 6291253; E-mail: wangl@ xmut.edu.cn

\begin{abstract}
In this study, corona gas-liquid dielectric barrier discharge reactor for phenol degradation was investigated. The discharge was formed between two needle metal electrodes and an aqueous solution surface where the counter electrode was submerged and separated by a quartz dielectric tube. Effects of solution conductivity, $\mathrm{pH}$ and gas composition on the degradation were examined. Experimental results showed that the degradation of phenol proceeded perfectly in a wide range of solution conductivity. In the process of degradation of phenol, ozone was additionally formed. The removal of phenol increased with the order: argon $<$ air $<$ oxygen. Increasing $\mathrm{pH}$ was favorable for phenol removal. When using argon as the discharge gas, the major degradation products were catechol, hydroquinone, hydroxyhydroquinone, acetic acid, formic acid and oxalic acid. In oxygen or air discharges, 1,4-benzoquinone and muconic acid were additionally formed. The energy efficiency of removal of phenol has been compared with other competitive processes.
\end{abstract}

Keywords: Plasma, Phenol, Degradation.

\section{INTRODUCTION}

Electrical discharges have been extensively investigated for the decontamination of water and wastewater ${ }^{1}$. Generally, an electric field of the order of $1 \mathrm{MV} / \mathrm{cm}$ is needed to initiate the corona-like discharge in liquids with low conductivities ${ }^{2}$. In comparison, contact glow discharge electrolysis (CGDE) can take place at highly conductive solutions using a low DC voltage (usually $500 \mathrm{~V}$ ). During CGDE, various active species such as $\mathrm{OH} \cdot \mathrm{H} \cdot \mathrm{and} \mathrm{O} \cdot$ are produced $^{3,4}$. These species, especially the $\mathrm{OH}$ - radicals, are particularly reactive toward the organic pollutants in water. Many organic compounds can be completely oxidized by means of $\mathrm{CGDE}^{5-7}$. However, CGDE uses precious platinum as the working electrode and must be operated in highly conductive solutions $(>3.0 \mathrm{mS} / \mathrm{cm})$, which greatly limits its industrial applications.

In order to improve the energy efficiency of pollutant removal, various types of reactors such as pulsed corona discharges above water ${ }^{8}$ and water-spray gliding arc have been developed $^{9}$. These processes were regarded as promising because of their higher energy utilization efficiency than that of direct liquid discharges since no energy was needed for bubble formation in liquid phase.

Recently, a system based on the gas-liquid dielectric barrier discharge (gas-liquid DBD) where water serves as one of the dielectric electrode was developed ${ }^{10}$. This process was also competitive in its simple power source and high energy utilization efficiency. The main disadvantage of this process was that the discharge was difficult to take place and the water surface deformed and even absorbed to the working electrode when plane-to-plane configuration was used ${ }^{11}$.

In this work, a special type of gas-liquid DBD reactor, which we called corona gas-liquid DBD where metal needles instead of plane dielectric sheet were used as the working electrode, has been developed. When the needle working electrode was used, electrical field near the electrode increased significantly and the discharge plasma became easier to form and stability of the discharge improved. In addition, when discharge forming gas was introduced through the working electrode to the reactor, deformation and absorbing of water surface to the working electrode was completely inhibited. Moreover, operation of the plasma discharge has demonstrated to be running perfectly in a wide range of solution conductivity. Phenol is widely used in industrial processes and a typical water pollutant. Tests on the phenol decomposition were performed to evaluate the operation performance of corona gas-liquid DBD for removal of aqueous pollutants.

\section{EXPERIMENTAL}

Experimental apparatus consisted of an AC high-voltage power supply and a cylindrical glass reactor, which are 
illustrated in Fig. 1. The working electrode was two copper wires $(\Phi=0.6 \mathrm{~mm})$ sealed into a glass tube (i.d. $4 \mathrm{~mm})$ with 2 mm exposed. The counter electrode was a stainless steel rod (i.d. $5 \mathrm{~mm}$ ) placed in another quartz tube filled with distilled water. The reaction vessel was coated by a water jacket, where the solution was maintained at $298 \pm 2 \mathrm{~K}$ by running tap water.

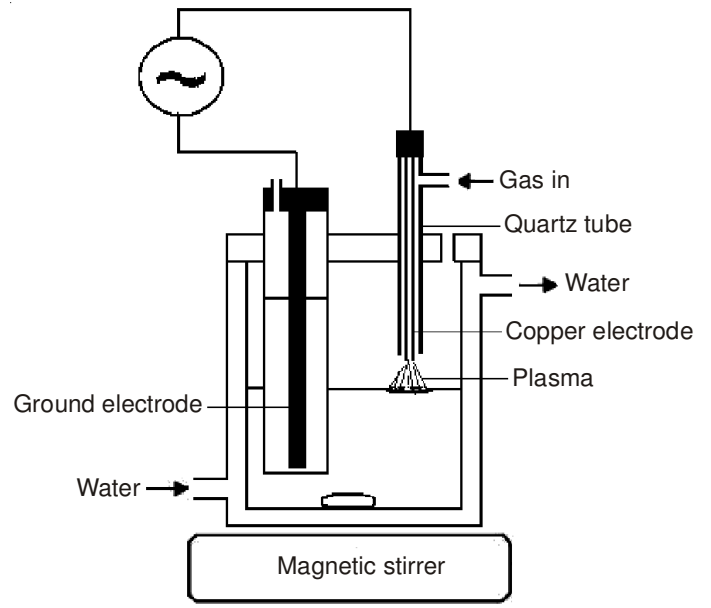

Fig. 1. Experimental diagram of the corona gas-liquid DBD

Two hundred $\mathrm{mL}$ portion of $100 \mathrm{mg} / \mathrm{L}$ phenol was poured into the reactor for treatment. Solution $\mathrm{pH}$ was adjusted by dilute sulfuric acid or sodium hydroxide to the desired value. Space distance between the working electrodes and the solution surface is $3 \mathrm{~mm}$. AC voltage of $8 \mathrm{kHz}$ was applied across the electrodes to initiate the reaction. Input power was fixed at $10 \mathrm{~W}$. In the course of discharge, argon, air or oxygen was passed to the solution separately as the discharge gases through the tube of the working electrodes at a rate of $25 \mathrm{~mL} / \mathrm{s}$. Solution conductivity was measured by a DDS-11A conductivity meter. Waveforms of voltage and current were recorded by a digital oscilloscope (Tektronix TDS2024B). The voltage was measured through a 1:1000 high voltage probe (Tektronix P6015A). The current was recorded by a current monitor (Pearson Electronics Inc.). Typical voltage and current waveforms are shown in Fig. 2.

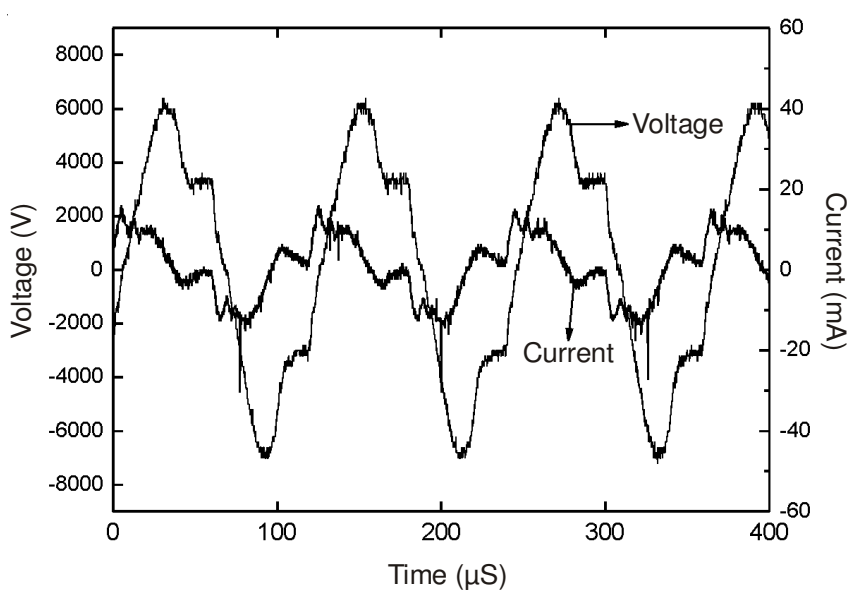

Fig. 2. Waveforms of voltage and current of corona gas-liquid DBD (gas composition, air; solution conductivity, $\left.250 \mu \mathrm{S} / \mathrm{cm} ; \mathrm{pH}_{0}, 6\right)$

During the discharge treatment, the solution was gently stirred with a magnetic stirrer and aliquots were periodically sampled out for analyses. Aromatic intermediate products as well as the un-degraded phenol were analyzed by means of high performance liquid chromatography (HPLC, Angilent 1100). Samples were analyzed using a $C_{18}$ reversed-phase column $(25.0 \mathrm{~cm} \times 4.6 \mathrm{~mm})$ with a mobile phase of $40 \%$ acetonitrile and $60 \%$ de-ionized water. Flow rate of the mobile phase was $0.8 \mathrm{~mL} / \mathrm{min}$. A UV detector was coupled to the HPLC to monitor the phenol and its degraded products. Phenol and the intermediate products were detected at 254 $\mathrm{nm}$. Organic acids, resulting from the phenol degradation were analyzed by ionic chromatography (IC, ICS-1100) with an Ion Pac AG-23 column and an aqueous solution of dilute $\mathrm{KOH}$ was used as the mobile phase, with a flow rate of $0.8 \mathrm{~mL} / \mathrm{min}$. The amount of total organic carbon (TOC) was measured by a TOC analyzer (TOC- $\mathrm{V}_{\mathrm{CSH}}$, Shimadzu). Ozone produced in the gas phase was analyzed by a gas analyzer (DR85C, Shenzhen, China).

\section{RESULTS AND DISCUSSION}

Degradation of phenol: Degradation of phenol proceeded smoothly when the solution containing phenol was subjected to corona gas-liquid DBD. Fig. 3 shows the removals of both phenol and TOC during the discharge treatment.

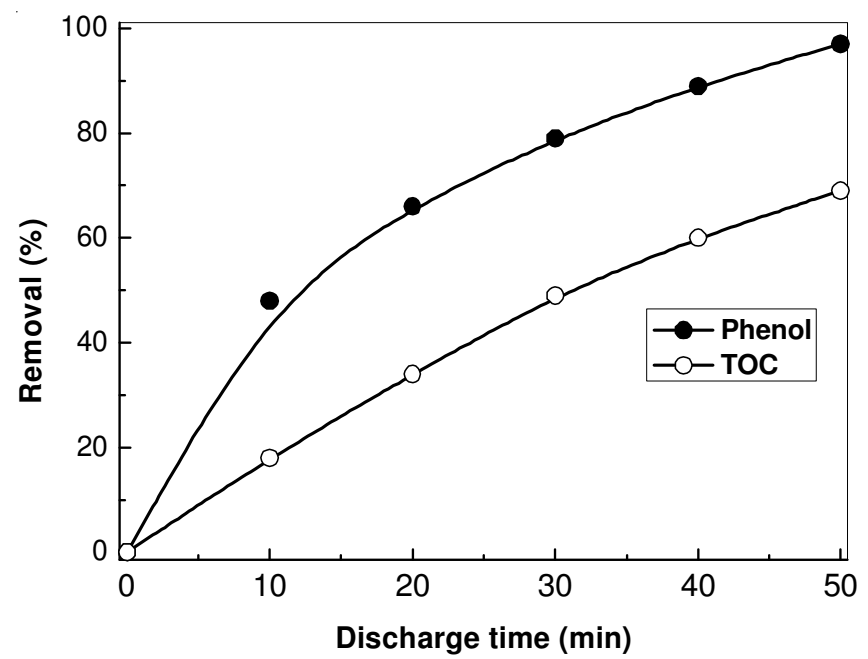

Fig. 3. Phenol and TOC removal during the corona gas-liquid DBD ([phenol $]_{0}, 100 \mathrm{mg} / \mathrm{L}$; gas composition, air; initial solution conductivity, $250 \mathrm{mS} / \mathrm{cm} ; \mathrm{pH}_{0}, 6$ )

It can be observed from Fig. 3 that phenol and TOC removed gradually with increasing treatment time. After 50 min. discharge, over $90 \%$ of phenol and $60 \%$ of TOC were removed. At $90 \mathrm{~min} .100 \%$ of phenol and $88 \%$ of TOC disappeared (Fig. 3), indicating that most carbon atoms of phenol were mineralized to carbon dioxide. It can also be seen from Fig. 3 that the decay rate of TOC was lower than that of phenol concentration, suggesting that some organic intermediate products were formed during the treatment. These intermediate products were mainly dihydroxybenzenes and organic acids.

Effects of solution conductivity on removal of phenol: Solution conductivity plays an important role in pollutant removal by electrical discharges. In this study, the solution conductivity was adjusted by addition of $\mathrm{Na}_{2} \mathrm{SO}_{4}$ to the desired 
value. Fig. 4 shows the phenol removals at $10 \mathrm{~min}$. discharge treatment under different initial conductivities, from $10 \mathrm{mS} /$ $\mathrm{cm}$ to $5000 \mathrm{mS} / \mathrm{cm}$.

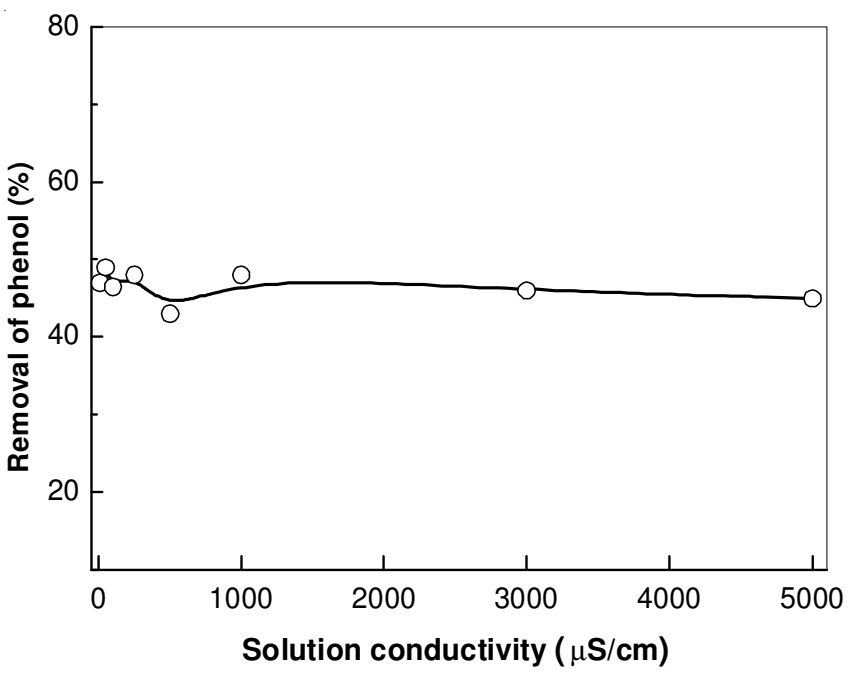

Fig. 4. Effects of solution conductivity on phenol removal ([phenol $]_{0}, 100$ $\mathrm{mg} / \mathrm{L}$; gas composition, air; $[\mathrm{pH}]_{0}, 6.0$ )

As seen from Fig. 4, the solution conductivity showed little influence on phenol removal. The average phenol removal at 10 min discharge treatment was $46.5 \%$, with relative standard deviation less than $5 \%$, from 10 to $5000 \mathrm{mS} / \mathrm{cm}$. In liquid phase pulsed corona discharges, decreasing conductivity $(<500 \mathrm{mS})$ was favorable for phenol removal ${ }^{12}$. In CGDE, however, the solution should have conductivity high enough (> $3000 \mathrm{mS}$ ) to make the discharge to occur. It is well known that the conductivity of real wastewater varies widely, from $10 \mu \mathrm{S} / \mathrm{cm}$ to $10 \mathrm{mS} / \mathrm{cm}$ or even higher. The present investigation demonstrates that the corona gas-liquid DBD would operate perfectly in industrial wastewater.

Effects of gas composition on removal of phenol: In order to investigate the role of discharge gases in phenol degradation, argon, oxygen or air was passed separately through the glass tube of needle working electrodes. The removal of phenol in the liquid phase and ozone formation in the gas phase under different discharge gases are shown in Fig. 5a-b, respectively.

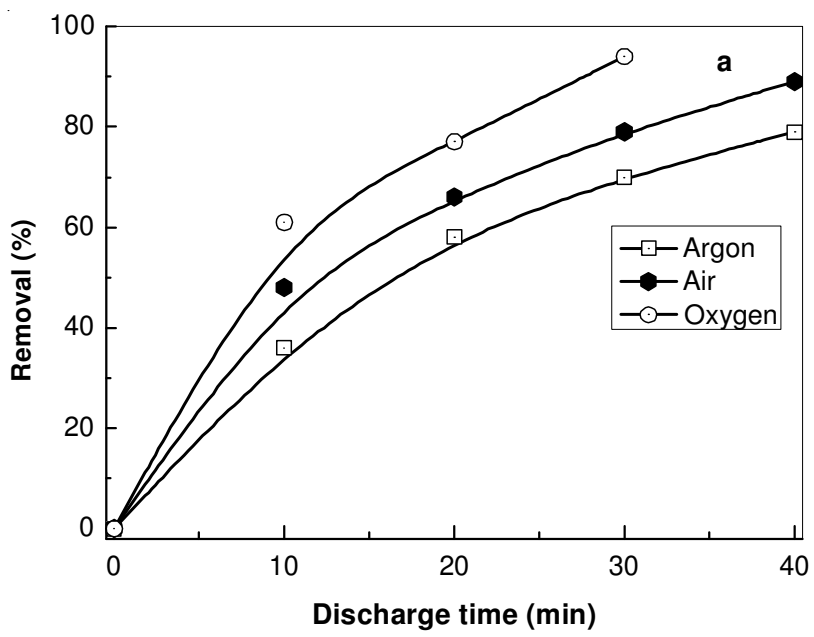

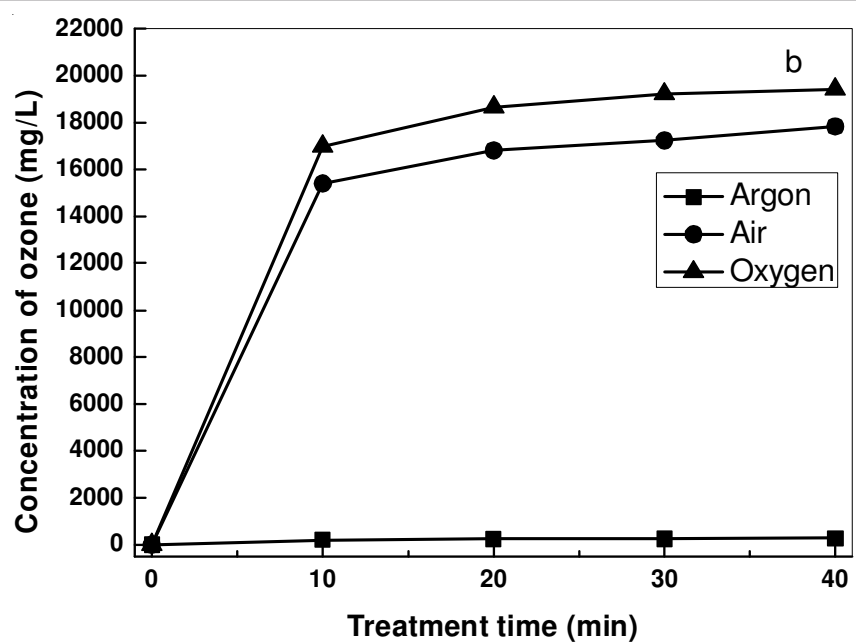

Fig. 5. Phenol removal in the liquid phase (a) and ozone formation in the gas phase (b) under different discharge gases ([phenol $]_{0}, 100 \mathrm{mg} / \mathrm{L}$; initial solution conductivity, $\left.250 \mathrm{mS} / \mathrm{cm} ;[\mathrm{pH}]_{0}, 6.0\right)$

As shown in Fig. 5a, phenol removal increased with the order: argon < air < oxygen. With $10 \mathrm{~min}$. discharge treatment, the phenol removal was 36, 48 and $61 \%$, in argon, air and oxygen, respectively. As indicated in Fig. 5b, there was a lot of ozone generated in the gas phase when air or oxygen was used as the discharge gas. Ozone is a very green oxidizer; the present process may also be a good ozonizer when the reactor was used for pollutants degradation. There were several factors to account for the effects of gas composition on phenol removal.

When the discharge takes place in inert gas argon, water molecules were decomposed by the energetic electrons from plasma into $\mathrm{OH}$. radicals and atomic hydrogen $(\mathrm{H} \cdot)$ in the solution:

$$
\mathrm{e}^{-}+\mathrm{H}_{2} \mathrm{O} \rightarrow \mathrm{OH} \cdot+\mathrm{H} \cdot+\mathrm{e}^{-}
$$

The $\mathrm{OH} \cdot$ radicals thus formed attack the benzene ring of phenol to form the corresponding $\mathrm{OH}$ adducts (ortho- and para-):<smiles>Oc1cccc(OCc2c(O)cccc2O)c1</smiles>

When air or oxygen is used as the discharge gas, besides reactions 1 and 2, molecular oxygen $\left(\mathrm{O}_{2}\right)$ will diffuse into the solution to oxidize the $\mathrm{OH}$ adducts and accelerate phenol removal ${ }^{13}$ :<smiles>Oc1ccccc1OCCCOc1cccc(O)c1O</smiles>

At the same time, $\mathrm{O}_{2}$ also dissociates in to atomic oxygen (O.) in the discharge zone, which will react with water (vapour and liquid) to form additional $\mathrm{OH} \cdot$ radicals and increase the phenol removal ${ }^{14}$ :

$$
\begin{aligned}
& \mathrm{e}^{-}+\mathrm{O}_{2} \rightarrow \mathrm{O}+\mathrm{O} \cdot+\mathrm{e}^{-} \\
& \mathrm{O} \cdot\left({ }^{1} \mathrm{D}\right)+\mathrm{H}_{2} \mathrm{O} \rightarrow 2 \mathrm{OH} \cdot
\end{aligned}
$$


In addition, ozone $\left(\mathrm{O}_{3}\right)$ will be produced through the reaction of $\mathrm{O} \cdot$ with $\mathrm{O}_{2}$ :

$$
\mathrm{O} \cdot+\mathrm{O}_{2}+\mathrm{M} \rightarrow \mathrm{O}_{3}+\mathrm{M}
$$

$\mathrm{O}_{3}$ is relatively long life and diffuse to the solution, where it can directly react with phenol ${ }^{15,16}$ or indirectly react with phenol through radical mechanism ${ }^{17}$. As both the content of $\mathrm{O}_{2}$ and the amount of $\mathrm{O}_{3}$ produced in oxygen were higher than those of air, the phenol removal rate with the oxygen as the discharge gas was the highest.

$\mathrm{pH}$ variation and effects of initial $\mathrm{pH}$ on removal of phenol: Special attention is paid to the $\mathrm{pH}$ effects on phenol removal. In order to better elucidate the role of $\mathrm{pH}$ in phenol degradation, $\mathrm{pH}$ variations during the discharge treatment under different discharge gases are given in Fig. 6 .

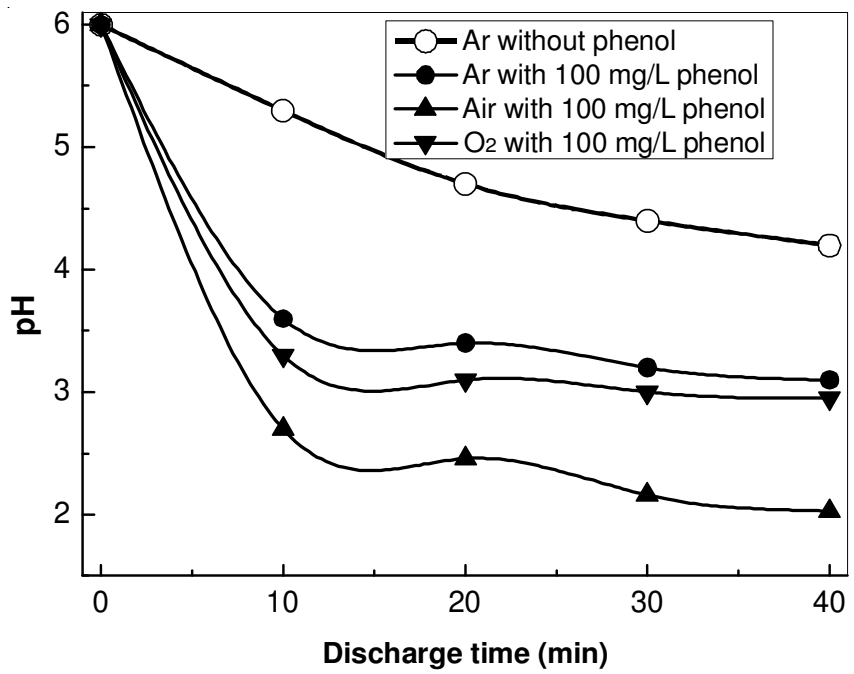

Fig. 6. $\mathrm{pH}$ variations during phenol degradation under different discharge gases ([phenol $]_{0}, 100 \mathrm{mg} / \mathrm{L}$; initial solution conductivity, $250 \mathrm{mS} /$ $\left.\mathrm{cm} ;[\mathrm{pH}]_{0}, 6\right)$

As indicated from Fig. 6, the solution $\mathrm{pH}$ drops during the discharge treatment. The drop rates increases in the order of argon < oxygen < air. In the case of argon, organic acids are produced and $\mathrm{pH}$ drops accordingly. In the case of oxygen, more organic acids are produced and $\mathrm{pH}$ drops more obviously than that in the case of argon (c.f. Fig. 10). In the air, nitrogen oxides are additionally produced and these nitrogen oxides dissolve in water and nitric acid was produced, which also contributes drops of $\mathrm{pH}^{14}$. In order to better elucidate the process, the nitric acid and nitrous acid formed in the solution were determined by IC and the results are shown in Fig. 7.

It can be observed from Fig. 7 that a great amount of nitric acid was produced during the discharge treatment. In contrast, the concentration of nitrous acid remained trace during the whole process. As nitric acid is strong acid, the $\mathrm{pH}$ drop was mainly caused by nitric acid formation during the air discharge.

Fig. 8 shows the initial solution $\mathrm{pH}$ on removal of phenol under different discharge gases.

As seen from Fig. 8, removal of phenol increases with increase of solution $\mathrm{pH}$ in the cases of argon or oxygen. However, the solution $\mathrm{pH}$ has almost no effect on phenol removal in the case of air. The phenomena can be explained by two reasons.

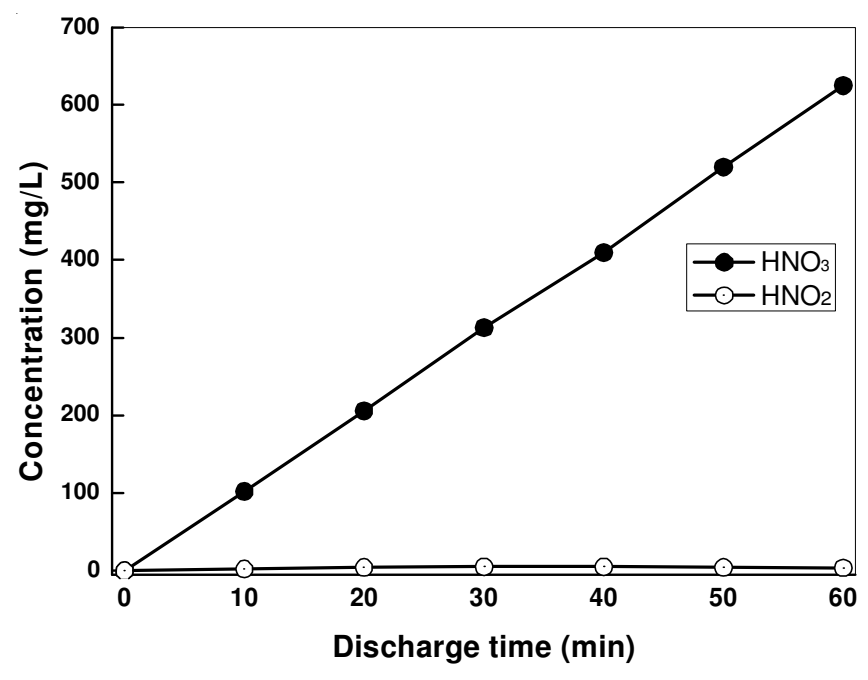

Fig. 7. Formation of $\mathrm{HNO}_{3}$ and $\mathrm{HNO}_{2}$ in the solution during corona gasliquid DBD in air ([phenol] $]_{0}, 100 \mathrm{mg} / \mathrm{L}$; initial solution conductivity, $\left.250 \mathrm{mS} / \mathrm{cm} ;[\mathrm{pH}]_{0}, 6\right)$

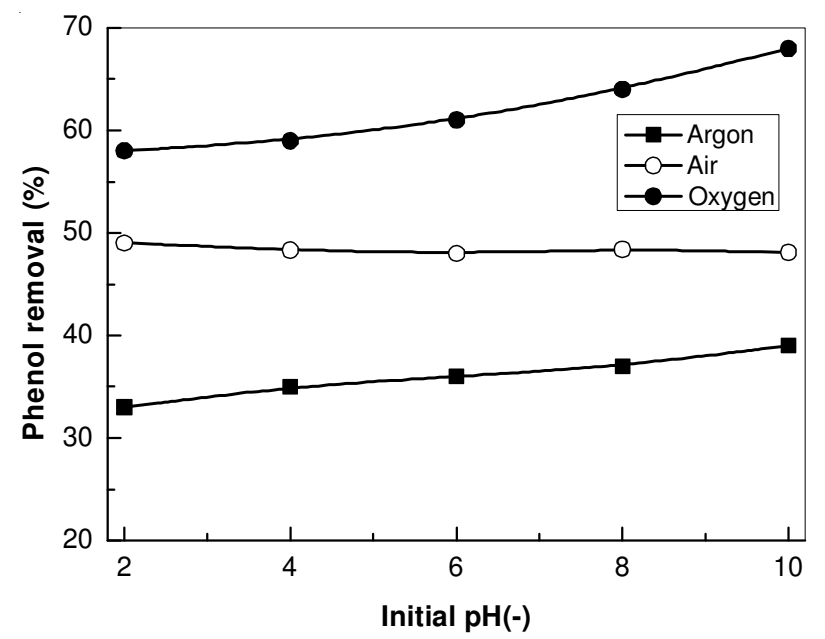

Fig. 8. Effects of initial $\mathrm{pH}$ on phenol removal under different discharge gases ([phenol] $0,100 \mathrm{mg} / \mathrm{L}$; initial solution conductivity, $250 \mathrm{mS} /$ $\mathrm{cm})$

One is that phenol is present in two forms in aqueous solution: dissociated and non-dissociated:<smiles></smiles>

With increase of $\mathrm{pH}$, the dissociated form prevails. As the dissociated form is more reactive than the un- dissociated ones toward the $\mathrm{OH}$ - radicals, the phenol removal increases with increasing $\mathrm{pH}^{18}$.

On the other hand, $\mathrm{O}_{3}$ is relatively inert to phenol. However, it can be converted into the much more reactive $\mathrm{OH}^{*}$ radicals in the presence of hydroxide ion ${ }^{17,19}$. Therefore, increase in $\mathrm{pH}$ promotes the $\mathrm{O}_{3}$ attack on phenol via $\mathrm{OH}$ radical reaction. When discharge takes place in air, the $\mathrm{pH}$ rapidly drops as nitric acid formation in liquid phase and influence of $\mathrm{pH}$ became un-auspicious. 
Intermediate products formation and possible degradation mechanism: In order to explore the possible degradation mechanism, HPLC and IC were used to identify the degradation products. Time evolution of the primary intermediate products during the corona gas-liquid DBD of $100 \mathrm{mg} / \mathrm{L}$ phenol detected by HPLC in argon and oxygen discharges is presented in Figs. 9a-b, respectively.
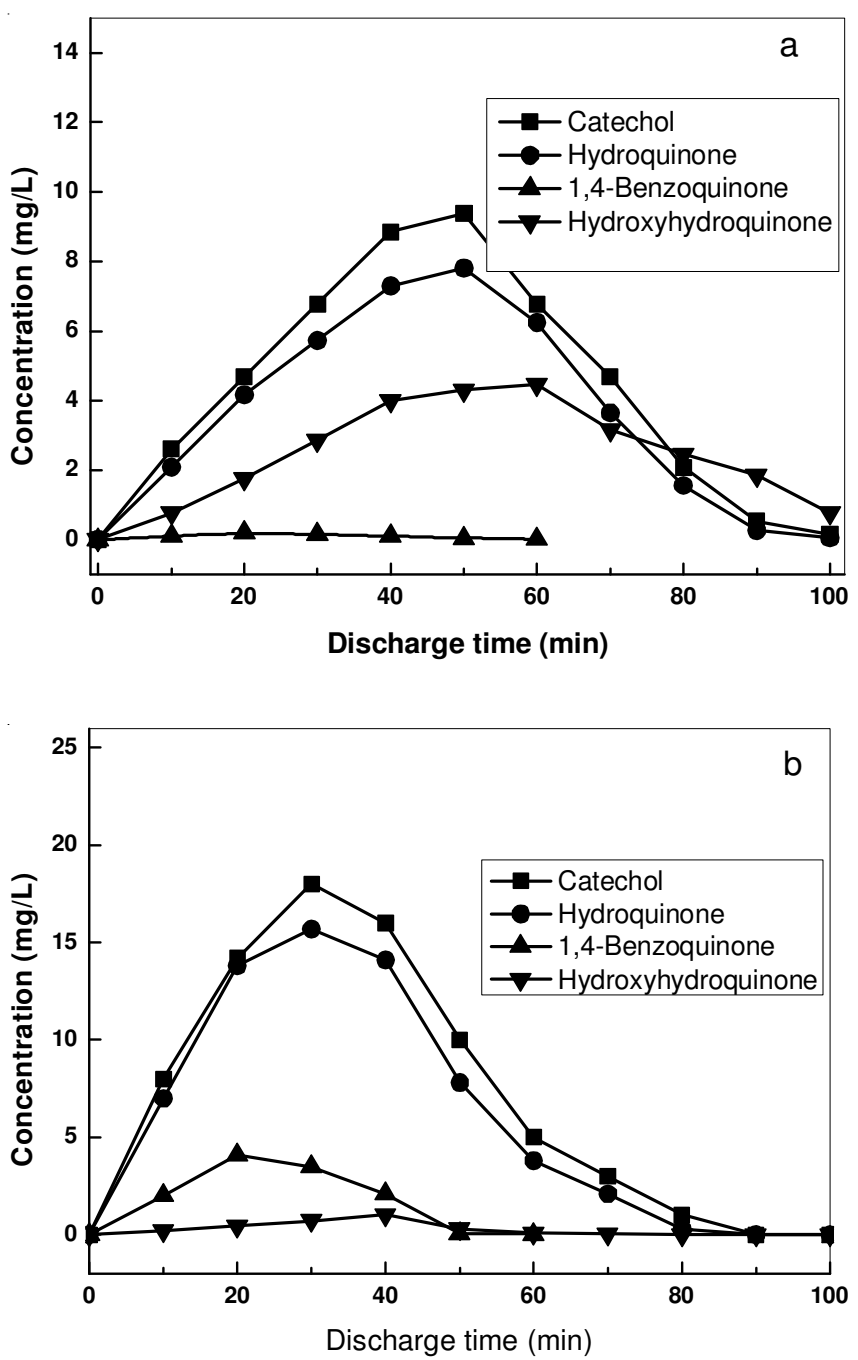

Fig. 9. Intermediate products formed during the corona gas-liquid DBD ([phenol] $]_{0}, 100 \mathrm{mg} / \mathrm{L}$; initial solution conductivity, $250 \mathrm{mS} / \mathrm{cm}$; $[\mathrm{pH}]_{0}, 6.0 ; \mathrm{a}$, argon; b, oxygen)

It can be found from Fig. 9 that the major intermediate products were catechol (CC), hydroquinone (HQ) and hydroxyhydroquinone (HHQ) when the discharge gas was argon. When discharge takes place in oxygen, the concentrations of $\mathrm{CC}$ and HQ are larger than those in argon discharge. In addition, the concentration of hydroxyhydroquinone was trace and 1,4-benzoquinone $(1,4-B Q)$ was greatly formed in oxygen discharge.

It is interesting to note that almost no 1,4-benzoquinone was detected in argon discharge, which is appreciably detected in oxygen discharge. In practice, when hydroquinone was subjected to argon discharge treatment, hydroxyhydroquinone yielded but no 1,4-benzoquinone was formed. The production of 1,4benzoquinone may be due to the oxidation phenoxyl radical by hydroperoxyl radicals $\left(\mathrm{HO}_{2}{ }^{\circ}\right)$ resulting from reaction $(3)^{20,21}$ :<smiles>Oc1cccc(Oc2ccccc2)c1</smiles><smiles>O=C1C=CC(O)C=C1C=Cc1ccccc1</smiles><smiles>O=C1C=CC(=O)C=C1</smiles>

No 1,2-benzoquinone was observed in the discharge treatment, whether in argon or in oxygen, possibly because the un-stability of the molecule.

Fig. 10 shows the time evolution of the primary carboxylic acids during the corona gas-liquid DBD of $100 \mathrm{mg} / \mathrm{L}$ phenol detected by IC in argon and oxygen discharges, respectively.
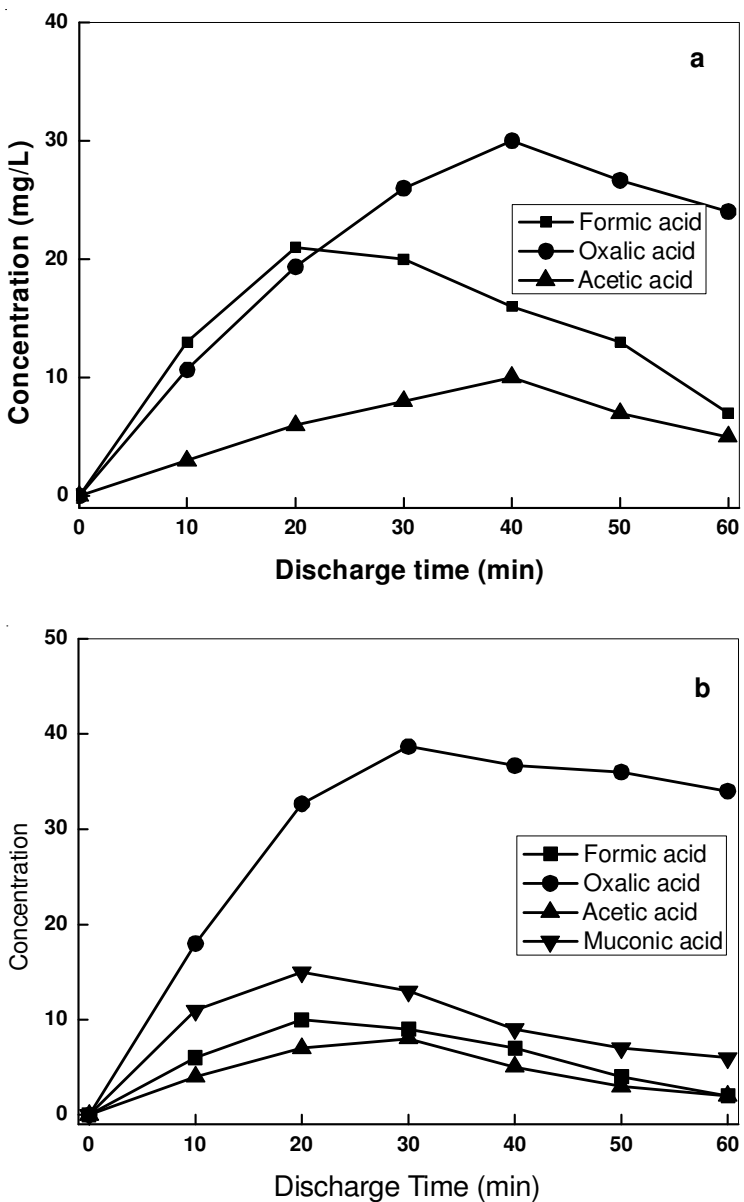

Fig. 10. Organic acids formed during the corona gas-liquid DBD ([phenol] $]_{0}$, $100 \mathrm{mg} / \mathrm{L}$; initial solution conductivity, $250 \mathrm{mS} / \mathrm{cm} ;[\mathrm{pH}]_{0}, 6.0$; a, argon; b, oxygen) 
It is shown from Fig. 10a that the major organic acids are oxalic acid, formic acid and acetic acid in argon discharge. The amount of formic acid is less than that of oxalic acid. When formic acid was used as a starting material, oxalic acid was yielded. However, when oxalic acid was used as the starting molecule, no formic acid was formed, indicating that the oxalic acid was yielded in part from the corona gas-liquid DBD of formic acid. These acids were eventually disappeared with longer discharge treatment. It is demonstrated from Fig. 10b that, during oxygen discharge, muconic acid was generated in the solution, in addition to the acids observed in argon discharge. The formation of muconic acid could be attributed to the direct ozonolysis of phenol ${ }^{21}$. Based on the above observations, the pathway for phenol degradation by corona gasliquid DBD is proposed in Scheme-I.

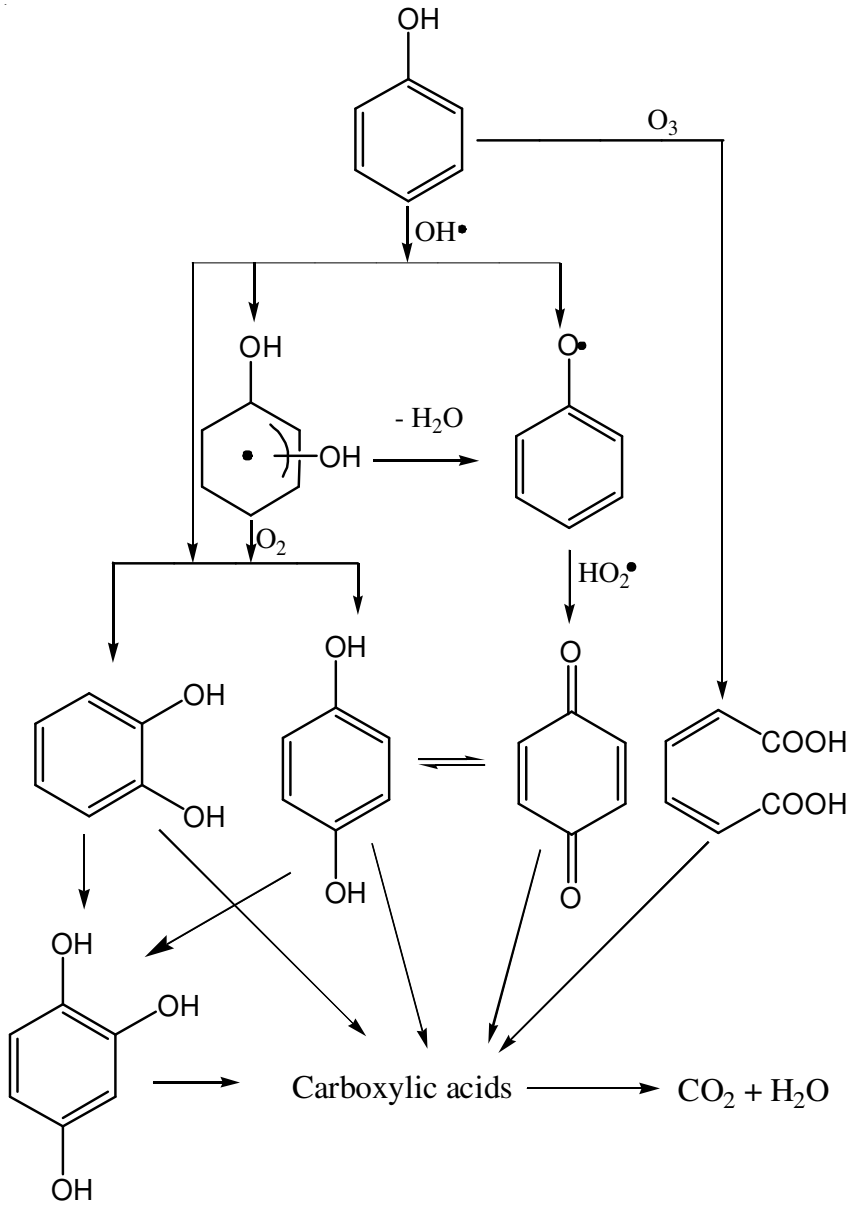

Scheme-I: Possible degradation pathway in corona gas-liquid DBD

It can be found from Scheme-I that phenol degradation in corona gas-liquid DBD can be mainly divided into three steps: (1) hydroxylating and ozonating of benzene nuclei, (2) cleavage of benzene nuclei to give carboxylic acids and (3) further oxidation to carbon dioxide. When hydroxylation occurs, it takes place preferentially at the ortho- and paraposition to the phenolic-OH group of phenol to give catechol and hydroquinone, respectively. Hydroxylation of catechol and hydroquinone gives to hydroxyhydroquinone. Further hydroxylation of the aromatic ring leads to the formation of carboxylic acids. Direct ozonation of phenol give muconic acid. As the organic acids are less reactive toward the hydroxyl radical, the second step is relatively slow. The last step is the mineralization to carbon dioxide.

Energy efficiency of phenol degradation: Energy efficiency is an important factor in comparison with other competitive processes. In this work, the energy efficiency for phenol degradation $\left(\mathrm{J}_{\text {phenol }}\right)$ is defined as:

$$
\mathrm{J}_{\text {Phenol }}=\frac{0.5 \mathrm{C}_{0} \mathrm{Vol}}{\mathrm{Pt}_{50}}
$$

where $\mathrm{C}_{0}$ is the initial phenol concentration ( $\left.\mathrm{mol} / \mathrm{L}\right)$, Vol is the solution volume (L), $\mathrm{P}$ is the input power (W) and $\mathrm{t}_{50}$ is the reaction time required for $50 \%$ of phenol conversion (s). Table-1 shows the energy efficiencies of different methods.

It can be seen that the energy efficiency of phenol degradation by corona gas-liquid DBD is comparable with that of pulsed corona discharges above water in air and is higher than those of pulsed corona discharge in water and CGDE. These demonstrated that corona gas-liquid DBD is a useful tool for removal of phenol.

\section{Conclusion}

Phenol can be efficiently decomposed by means of corona gas-liquid dielectric barrier discharge. Its degradation proceeded perfectly in a wide range of solution conductivity. Its removal rate increased with the order: argon < air < oxygen. There was a lot of ozone produced in the gas phase when air or oxygen was used as the discharge gas. Solution $\mathrm{pH}$ had little effect on the removal in the case of air. In the case of oxygen or argon, the removal increased with increasing solution $\mathrm{pH}$. When using argon as the discharge gas, the major degradation products were catechol, hydroquinone, hydroxyhydroquinone, acetic acid, formic acid and oxalic acid. In oxygen or air discharges, catechol, hydroquinone, 1,4-benzoquinone, acetic acid, formic acid, oxalic acid and muconic acid were the main intermediate products. The final products were carbon dioxide. As nitric acid was generated in the liquid during air discharge, oxygen may be the optimum discharge gas for phenol removal. The present study demonstrated that corona gas-liquid dielectric barrier discharge be a promising

TABLE-1

COMPARISON OF ENERGY EFFICIENCY WITH OTHER COMPETITIVE TECHNOLOGIES FOR PHENOL REMOVAL

\begin{tabular}{cccc}
\hline $\mathrm{C}_{0}\left(10^{-3} \mathrm{~mol} / \mathrm{L}\right)$ & Method & $\mathrm{J}_{\text {phenol }}\left(10^{-9} \mathrm{~mol} / \mathrm{J}\right)$ & References \\
\hline 1.06 & Corona gas-liquid DBD; $200 \mathrm{~mL} ; 10 \mathrm{~W} ;$ argon, $\mathrm{pH}_{0} 6.0$ & 11.5 & This work \\
1.06 & Corona gas-liquid DBD; $200 \mathrm{~mL} ; 10 \mathrm{~W} ;$ air; $\mathrm{pH}_{0}, 6.0$ & 16.7 & This work \\
1.06 & Corona gas-liquid DBD; $200 \mathrm{~mL} ; 10 \mathrm{~W} ;$ oxygen; $\mathrm{pH}, 10.0$ & 23.8 & This work \\
1.0 & Pulsed corona discharge above water; $500 \mathrm{~mL} ; 1 \mathrm{~W} ;$ air & 18.0 & 8 \\
0.1 & Pulsed corona discharge above water; $500 \mathrm{~mL} ; 1 \mathrm{~W} ;$ oxygen & 68.0 & 8 \\
0.53 & Pulsed corona discharge in water; $250 \mathrm{~mL} ; 42 \mathrm{~W}$ & 3.7 & 8 and therein \\
1.06 & CGDE; $150 \mathrm{~mL} ; 50 \mathrm{~W} ; 1.0 \mathrm{mmol} / \mathrm{L} \mathrm{Fe}{ }^{3+}$ & 8.8 & 7 \\
\hline
\end{tabular}


process for aqueous pollutants removal. Further studies on the mechanistic aspects are underway.

\section{ACKNOWLEDGEMENTS}

This work was supported by the National Science Foundation of China (51008262), the Outstanding University Young Research Personnel Training Foundation of Fujian Province, China (JK2011048), the Science and Technology Plan Project of Xiamen City (3502Z20133040) and the Open Foundation of the Key Laboratory of Urban Environment and Health, Chinese Academy of Sciences (KLUEH201104).

\section{REFERENCES}

1. B.R. Locke, M. Sato, P. Sunka, M.R. Hoffmann and J.S. Chang, Ind. Eng. Chem. Res., 45, 882 (2006).

2. H.M. Jones and E.E. Kunhardt, J. Appl. Phys., 77, 795 (1995).

3. K.S. Susanta, S. Rajeshwar and K.S. Ashok, J. Electrochem. Soc., 145, 2209 (1998).

4. Y.J. Liu, B. Sun, L. Wang and D.G. Wang, Plasma Chem. Plasma Process., 32, 359 (2012)

5. M. Tezuka and M. Iwasaki, Thin Solid Films, 316, 123 (1998).
6. J. Gao, Y. Liu, W. Yang, L. Pu, J. Yu and Q. Lu, Plasma Sources Sci. Technol., 12, 533 (2003).

7. L. Wang and Y.J. Liu, Plasma Chem. Plasma Process., 32, 715 (2012).

8. W.F.L.M. Hoeben, E.M. Veldhuizen, W.R. Rutgers and G.M.W. Kroesen, J. Phys. D: Appl. Phys., 32, L133 (1999).

9. R. Burlica, W. Finney and B. Locke, IEEE Ind. Trans., 49, 1098 (2013).

10. M.M. Kuraica, B.M. Obradovic, D. Manojlovic, D.R. Ostojic and J. Puric, Vacuum, 73, 705 (2004).

11. P. Baroch, N. Saito and O. Takai, J. Phys. D: Appl. Phys., 41, 085207 (2008).

12. F. Wang, J. Li, Y. Wu, H. Wang and G. Li, High Voltage Eng., 33, 124 (2007).

13. E. Mvula, M.N. Schuchmann and C. von Sonntag, J. Chem. Soc. Perkin Trans. 2, 3, 264 (2001).

14. U. Kogelschatz, Plasma Chem. Plasma Process., 23, 1 (2003).

15. J. Hoigné and H. Bader, Water Res., 17, 173 (1983).

16. J. Hoigné and H. Bader, Water Res., 17, 185 (1983).

17. J. Staehelin and J. Hoigne, Environ. Sci. Technol., 16, 676 (1982).

18. G.V. Buxton, C.L. Greenstock, W.P. Helman and A.B. Ross, J. Phys. Chem. Ref. Data, 17, 513 (1988).

19. W.H. Glaze, J.W. Kang and D.H. Chapin, Ozone Sci. Eng., 9, 335 (1987).

20. C. von Sonntag and H.P. Schuchmann, Angew. Chem. Int. Ed., 30, 1229 (1991).

21. E. Mvula and C. von Sonntag, Org. Biomol. Chem., 1, 1749 (2003). 